\title{
Perbandingan Model Problem Based Learning dan Inquiry Terhadap Hasil Belajar Siswa di Mts Negeri 1 Rantauprapat
}

\section{Comparison Of Problem Based Learning and Inquiry Models On Results Of Student Learning in MTs Negeri 1 Rantauprapat}

\author{
Maharani Gultom*, Dini Hariyati Adam, Ika Cahastanti, Zunaidy Abdullah Siregar \\ Program Studi Pendidikan Biologi, Fakultas Keguruan dan Ilmu Pendidikan, Universitas Labuhanbatu. \\ *Corespondent email: maharanigultom.mpd@gmail.com
}

Received: 11 March 2020 | Accepted: 28 June 2020 | Published: 20 July 2020

\begin{abstract}
Abstrak. Hasil belajar yang masih rendah menuntut guru untuk menggunakan model pembelajaran yang efektif untuk meningkatkan hasil belajar siswa. Adapun tujuan dari penelitian ini adalah untuk mengetahui apakah terdapat perbedaan hasil belajar dengan menggunakan Model Problem Based Learning (PBL) dan Inquiry pada siswa kelas VIII di MTs Negeri 1 Rantauprapat. Jenis penelitian ini adalah quasi eksperimen. Penelitian ini menggunakan dua kelas yang dipilih dengan menggunakan Teknik Purposive Sampling. Kedua kelas diberikan perlakuan yang bebeda dengan materi yang sama. Untuk memperoleh data, peneliti menggunakan tes yang terlebih dahulu dilakukan uji coba instrumen meliputi uji validitas dan uji reliabilitas. Selanjutnya analisis data menggunakan uji normalitas, uji homogenitas, dan uji hipotesis dengan menggunakan uji t. Hasil penelitian menunjukkan bahwa terdapat perbedaan hasil belajar menggunakan model pembelajaran Problem Based Learning (PBL) dan Inquiry pada siswa kelas VIII di MTs Negeri 1 Rantauprapat dengan diperoleh signifikansi $<0,05$ yaitu $0,000<0,05$. Selanjutnya, nilai rata-rata kelas yang menggunakan Model Problem Based Learning (PBL) lebih tinggi dari pada kelas dengan Inquiry, yaitu dengan nilai rata-rata masingmasing kelas adalah 80,00 dan 72,77. Hal ini menunjukkan bahwa Model Problem Based Learning (PBL) lebih unggul daripada Inquiry.

Kata kunci: Model Pembelajaran, Problem Based Learning, Inquiry, Hasil Belajar.
\end{abstract}

\begin{abstract}
Low learning outcomes require teachers to use effective learning models to improve student learning outcomes. The purpose of this study is to determine whether there are differences in learning outcomes by using the Model Problem Based Learning (PBL) and Inquiry in class VIII students in MTs Negeri 1 Rantauprapat. This type of research is a quasi-experimental. This study uses two classes selected using the Purposive Sampling Technique. Both classes are given different treatment with the same material. To obtain data, researchers used tests that were first tested by instruments including validity and reliability tests. Furthermore, data analysis uses the normality test, homogeneity test, and hypothesis testing using the t test. The results showed that there were differences in learning outcomes using the Problem Based Learning (PBL) and Inquiry learning models for Grade VIII students at MTs Negeri 1 Rantauprapat with significance obtained $<0.05$ ie 0,000 $<0.05$. Furthermore, the average grade of the class using the Problem Based Learning $(P B L)$ model is higher than the class with Inquiry, namely the average value of each class is 80.00 and 72.77. This shows that the Problem Based Learning (PBL) Model is superior to Inquiry.
\end{abstract}

Keywords: Learning Model, Problem Based Learning, Inquiry, Learning Outcomes.

\section{PENDAHULUAN}

Pendidikan adalah suatu proses dalam rangka mempengaruhi peserta didik dalam upaya menyesuaikan diri sebaik mungkin dengan lingkungannya dan dengan demikian akan menimbulkan perubahan dalam dirinya yang memungkinkan untuk berfungsi dalam kehidupan masyarakat (Mutmainnah at al., 2019). Pertumbuhan dan perkembangan peserta didik bergantung pada dua unsur yang saling mempengaruhi, yaitu bakat yang dimiliki oleh peserta didik sejak lahirn dan lingkungan yang mempengaruhi hingga bakat itu tumbuh dan berkembang. 
Dua unsur tersebut sama pentingnya, namun ada kemungkinan pertumbuhan dan perkembangan itu disebabkan oleh bakat saja atau pengaruh lingkungan saja (Hadiati dan Nasution, 2016).

Pendidikan IPA merupakan bagian dari pendidikan yang umumnya memiliki peran penting dalam peningkatan mutu pendidikan, khusunya di dalam menghasilkan peserta didik yang berkualitas, yaitu manusia yang mampu berfikir kritis, kreatif, logis dan berinsiatif. Pembelajaran IPA merupakan suatu wahana pendidikan untuk mengembangkan semua potensi yang dimiliki siswa, termasuk kemampuan keterampilan proses, kemampuan memecahkan masalah, pengamatan, kebiasaan bekerja dan mandiri, jujur, berdisiplin, memiliki sikap sosial yang baik, serta berbagai keterampilan yang diperlukan dalam kehidupan masyarakat (Unaenah dan Muawiyah, 2019).

Sekolah sebagai suatu lembaga pendidikan formal merencanakan berbagai macam lingkungan pendidikan yang menyediakan berbagai kesempatan bagi peserta didik untuk melakukan berbagai kegiatan belajar. Masalah utama dalam pembelajaran pendidikan formal (sekolah) dewasa ini adalah masih rendahnya daya serap peserta didik, dimana rata-rata hasil belajar peserta didik yang senantiasa masih sangat memprihatinkan. Prestasi ini tentunya merupakan hasil kondisi pembelajaran yang masih bersifat konvensional. Dalam pembelajaran ini suasana kelas cenderung berpusat pada guru sehingga siswa menjadi pasif. Meskipun demikian, banyak guru lebih suka menerapkan model tersebut karena cukup dengan menjelaskan konsep-konsep yang ada pada buku ajar (Rahayu et al., 2015).

Untuk mencapai hasil belajar yang optimal, dalam merancang program pembelajaran dan kegiatan pembelajaran bagi siswa, guru harus memperhatikan karakteristik efektif siswa, siswa juga harus berperan aktif di dalamnya. Salah satu cara agar siswa berperan aktif adalah dengan menciptakan suasana belajar yang menyenangkan. Siswa harus dilatih untuk berkreasi, mandiri, bertanggung jawab, dan dapat memecahkan masalah-masalah yang dihadapi (Amir, 2010).

Berdasarkan hasil wawancara dengan guru mata pelajaran IPA di MTs Negeri 1 Rantauprapat menyatakan bahwa pembelajaran masih terpusat pada guru. Siswa hanya mendengarkan dan mencatat yang disampaikan dan tertulis di papan. Siswa juga kurang aktif dalam menanyakan apa yang belum dimengerti oleh siswa bahkan siswa lebih cenderung mengobrol dengan teman lainnya saat pembelajaran di kelas. Selain itu, hasil dari wawancara dengan guru mata pelajaran IPA siswa kelas VII diperoleh informasi bahwa hasil belajar siswa masih belum memuaskan, berdasarkan standar ketuntasan hasil belajar yang ditetapkan di MTs Negeri 1 Rantauprapat adalah 75, maka hasil belajar peserta didik belum mencapai ketuntasan.

Model yang efektif dalam meningkatkan hasil belajar yaitu model PBL dan model inquiry. Model pembelajaran PBL adalah pembelajaran yang menyuguhkan berbagai situasi bermasalah yang autentik dan bermakna kepada peserta didik agar mereka menyelidikinya. Dengan demikian dapat dipahami bahwa, model pembelajaran PBL adalah pembelajaran berbasis masalah yang dikembangkan untuk merangsang peserta didik berpikir tingkat tinggi dan bagaimana mereka belajar. Selain itu model PBL sangat efektif dalam meningkatkan hasil belajar (Sudewi at al., 2014).

Sedangkan Inquiry bertujuan memperoleh dan mendapatkan informasi dengan melakukan observasi atau eksperimen untukmencari jawaban atau menyelesaikan masalahh terhadap pertanyaan atau rumusan masalah dengan mengunakan kemampuan berfikir kritis dan logis. Metode inquiry learning adalah metode pembelajaran yang memberi kesempatan pada peserta didik untuk terlibat secara aktif dalam proses pembelajaran melalui penyelidikan, sehingga 
melatih peserta didik untuk kreatif dan berpikir kritis untuk menemukan sendiri suatu pengetahuan. Akhir dari metode inquiry learning adalah peserta didik mampu menggunakan pengetahuannya untuk memecahkan permasalahan yang dihadapinya berdasarkan fakta-fakta yang ada (Handoyono dan Arifin, 2016).

Berdasarkan pemaparan diatas penelitian ini bertujuan untuk mengkaji perbandingan pembelajaran Problem Based Learning (PBL) dan inquiry terhadap hasil belajar siswa pada di MTs Negeri 1 Rantauprapat.

\section{METODE PENELITIAN}

Penelitian dilaksanakan di MTs Negeri Rantauprapat yang beralamat di Jl. Kampung Baru Gg. Tsanawiyah No.150 Rantauprapat dan waktu penelitian dilaksanakan pada bulan April sampai dengan Mei pada semester II T.A 2018/2019. Jenis penelitian ini yaitu quasi eksperimen. Populasi penelitian ini adalah seluruh siswa kelas VIII MTs Negeri Rantauprapat Tahun Pelajaran 2018/2019. Sampel yang digunakan dalam penelitian ini adalah sebagian anggota populasi. Pengambilan sampel dengan menggunakan Purposive Sampling yaitu teknik pengambilan sampel dengan pertimbangan tertentu yang dilakukan dalam penelitian yaitu berdasarkan kemampuan awal (pretest) yang setara pada kedua kelas penelitia. Berdasarkan tekhnik pengambilan sampel diperoleh kelas VIII-D sebagai kelas eksperimen yang dibelajarkan dengan model pembelajaran inquiri dan VIII-I sebagai kelas kontrol.

Instrumen penelitian yang digunakan untuk pengumpulan data penilitian adalah tes hasil belajar dan angket kecakapan sosial. Tes hasil belajar disusun dalam bentuk tes objektif atau pilihan berganda. Bentuk tes dikembangkan berdasarkan kemampuan kognitif yang diukur berdasarkan dimensi proses taksonomi bloom yang telah direvisi. Sebelum dilakukan penelitian, dilakukan uji coba tes dengan tujuan untuk mengetahui sejauh mana suatu alat mampu mengukur apa yang seharusnya diukur (validitas) dan seberapa jauh suatu alat pengukur tersebut andal (reliabel), tingkat kesukaran tes, dan daya pembeda tes. Pengujian hipotesis dengan uji t menggunakan mean atau rata-rata nilai tes antara dua kelompok kelas eksperimen (Riyanto, 2001). Data dianalisis dengan menggunakan aplikasi SPSS 19.0 for windows.

\section{HASIL DAN PEMBAHASAN \\ Uji Deskriptif}

Pada penelitian ini, data penelitian diperoleh dari hasil belajar siswa yang terdiri dari 60 siswa untuk kelas eksperimen yaitu 30 siswa untuk pembelajaran problem based learning dan 30 siswa untuk pembelajaran kooperatif tipe inquiry.

Sebelum perlakuan pembelajaran dilakukan pada kelas eksperimen terlebih dahulu diberikan pretes untuk mengetahui tingkat kemampuan awal siswa tentang materi yang diberikan. Dari data pretes siswa pada kelas dengan pembelajaran problem based learning diperoleh nilai tertinggi 62, nilai terendah 40 dengan rata-rata 52,60 dan standar deviasi 5,98. Pada kelas inquiry diperoleh nilai tertinggi 62, nilai terendah 40 dengan rata-rata 51,07 dan standar deviasi 6,07. 
Tabel 1. Nilai analisis pretes siswa pada kelas PBL dan kelas Inquiry

\begin{tabular}{lcc} 
Nilai & Pretes kelas PBL & Pretes kelas inquiry \\
\hline Minimum & 40 & 40 \\
Maximum & 62 & 62 \\
Median & 52,00 & 50,00 \\
Mean & 52,60 & 51,07 \\
Std. Deviation & 5.986 & 6.074 \\
\hline
\end{tabular}

Berdasarkan hasil uji normalitas Kolmogorov-Smirnov, bahwa pretes hasil belajar siswa pada kelas problem based learning sebesar 0,174 , pretes hasil belajar siswa pada kelas inquiry sebesar 0,136, dengan signifikansi > 0,05, sehingga $\mathrm{H}_{0}$ diterima. Pretes hasil belajar dari kelas problem based learning dan inquiry berdistribusi normal.

Selanjutnya setelah perlakuan pembelajaran dilakukan diberikan postes pada untuk mengetahui hasil belajar siswa. Dari data hasil postest siswa pada kelas dengan model pembelajaran problem based learning diperoleh nilai tertinggi 87, nilai terendah 65 dengan ratarata 80,00 dan standar deviasi 5,35. Pada kelas dengan model pembelajaran inquiry diperoleh nilai tertinggi 80 dan nilai terendah 62 dengan rata-rata 72,77 dan standar deviasi 6,306.

Tabel 2. Nilai analisis postes siswa pada kelas PBL dan kelas Inquiry

\begin{tabular}{lcc}
\hline Nilai & Postest kelas PBL & Postest kelas Inquiry \\
\hline Maximum & 87 & 80 \\
Minimum & 65 & 62 \\
Median & 80,00 & 74,00 \\
Mean & 80,00 & 72,77 \\
Std. Deviation & 5,356 & 6,306 \\
\hline
\end{tabular}

Berdasarkan hasil Uji Normalitas Kolmogorov-Smirnov, bahwa postes hasil belajar siswa pada kelas PBL sebesar 0,071, postes hasil belajar siswa pada kelas inquiry sebesar 0,113, dengan signifikansi $>0,05$, sehingga $\mathrm{H}_{0}$ diterima. Postes hasil belajar dari kelas problem based learning dan inquiry berdistribusi normal.

Uji homogenitas dipergunakan untuk mengetahui apakah data yang digunakan berasal dari populasi yang memiliki homogenitas varians yang sama. Homogenitas data diuji dengan uji Levene's. Hasil uji homogenitas berdasarkan uji Levene's menunjukkan bahwa seluruh kelompok data yang dianalisis memiliki varians yang homogen, atau data berasal dari populasipopulasi dengan varian yang sama.

Berdasarkan hasil Uji Levene's, untuk kemampuan awal siswa (pretes) diperoleh taraf signifikansi $\mathrm{P}=0,998>0,05$ dan untuk hasil belajar (postes) diperoleh taraf signifikansi $\mathrm{P}=$ $0,258>0,05$. Oleh karena probabilitas dari seluruh kelompok data tersebut lebih besar daripada $\alpha$ $=0,05$, maka data pretes dan postes siswa memiliki varians yang sama (Homogen). Uji normalitas menunjukkan bahwa sebaran data hasil belajar siswa berdistribusi secara normal sedangkan uji homogenitas memperlihatkan sebaran data hasil belajar siswa dinyatakan homogen. Hal ini menunjukkan bahwa uji prasyarat statistik parametrik dengan uji t terpenuhi dan dapat diterapkan. 


\section{Uji Hipotesis}

Uji hipotesis dengan uji t menunjukkan bahwa terdapat perbedaan yang signifikan antara hasil belajar siswa yang dibelajarkan dengan model pembelajaran problem based learning dan inquiry dengan signifikansi $\mathrm{P}=0,000<0,05$ ). Sehingga hipotesis nol yang menyatakan bahwa tidak terdapat perbedaan hasil belajar siswa yang dibelajarkan dengan pembelajaran problem based learning dibandingkan dengan pembelajaran inquiry ditolak dan hipotesis alternatif yang menyatakan bahwa terdapat perbedaan hasil belajar siswa yang dibelajarkan dengan pembelajaran problem based learning dibandingkan dengan pembelajaran inquiry diterima.

Berdasarkan analisis data hasil penelitian dengan menggunakan analisis Independent Sample t-test diperoleh bahwa hasil belajar biologi siswa yang dibelajarkan dengan strategi PBL dan inquiry terdapat perbedaan yang signifikan antara keduanya dalam mempengaruhi hasil belajar siswa.

Perbedaan keefektivan kedua proses pembelajaran dapat dilihat dari hasil belajar siswa dan proses pembelajaran pada kelas eksperimen 1 yang lebih baik jika dibandingkan dengan kelas eksperimen 2. Hal ini dikarenakan pada pembelajaran PBL, guru memberikan kebebasan kepada siswa untuk berfikir dan mencari ide gagasan dari berbagai sumber serta melakukan uji coba penyelesaian dari ide yang telah diperolehnya. Guru yang berperan sebagai fasilitator juga memberikan bimbingan kepada siswa dengan memberikan beberapa pertanyaaan yang mengarahkan siswa untuk menemukan informasi yang dibutuhkan. Model pembelajaran ini jelas terlihat efektif mampu membuat siswa lebih termotivasi, aktif, bersemangat, dan percaya diri ketika menjelaskan hasil diskusi penyelesaian soal di depan kelas. Keaktifan motorik siswa lebih terlihat pada model pembelajaran PBL karena pada kelas dengan moel pembelajaran PBL siswa lebih bebas dalam melakukan percobaan tapi masih terkontrol dalam pengawasan guru dan siswa secara kerjasama dalam melakukan percobaan sehingga setiap siswa aktif dalam melakukan percobaan (Pranoto at al., 2017).

Ide-ide yang ditemukan oleh siswa secara mandiri membuat siswa lebih mudah dalam menyelesaikan soal-soal yang diberikan. Ketika diberikan soal lain, siswa mampu untuk menyelesaikan dengan baik dan benar. Kegiatan dalam proses belajar mengajar dengan m,enggunakan model pembelajaran PBL yang melibatkan siswa secara langsung dalam menemukan konsep penyelesaian masalah secara mandiri akan membuat siswa dapat menemukan pengetahuan dengan lebih mudah dan bertahan lama dalam ingatannya (Putri dan Agustyaningrum, 2017). Keadaan tersebut menunjukkan bahwa BPL mampu meningkatkan pengetahuan serta mengembangkan keterampilan berpikir siswa. Pemecahan masalah yang dilakukan secara mandiri ini tentunya dapat memberikan suatu pengalaman konkret yang dapat digunakan untuk memecahkan masalah-masalah serupa, karena pengalaman tersebut akan memberikan makna tersendiri bagi siswa (Dinullah, 2018).

Penelitian ini didukung oleh penelitian yang dilakukan oleh (Hadiati dan Nasution, 2016) yang menyatakan bahwa model pembelajaran PBL dapat meningkatkan hasil belajar siswa. Dalam pelaksanaan pembelajaran dengan model pembelajaran PBL siswa melakukan aktifitas nyata untuk memecahkan masalah yang terjadi dalam proses belajar mengajar, mereka juga dituntut untuk melakukan penalaran yang lebih dalam proses pembelajaran. Sedangkan dalam pelaksanaan pembelajaran dengan model pembelajaran inquiry siswa dapat mampu 
mengembangkan hipotesis yang terdapat dalam pikirannya, kemudian dapat berpikir secara divergen. Penggunaan model inquiry sangat berkaitan dengan peningkatan kemandirian siswa.

Berbeda dengan penelitian yang dilakukan oleh Mutmainnah et al., (2019) yang melaporkan bahwa model pebelajaran inkuiri terbimbing memiliki pengaruh yang lebih besar terhadap hasil belajar IPA. Hal yang mendasari model pembelajaran inkuiri terbimbing lebih baik dari model pembelajaran problem based learning yaitu dalam proses pembelajaran khususnya dalam pembuatan rumusan masalah inkuiri terbimbing dalam prosesnya dibimbing oleh guru, sehingga lebih mudah dalam menemukan rumusan masalah yang sesuai.

Penelitian yang dilakukan oleh Mayasri dan Rahmayani, (2019) melaporkan bahwa penggunaan model pembelajaran PBL dan inquiry memiliki perbedaan signifikan pada rata-rata hasil belajar dan kemampuan berpikir kritis mahasiswa. Keadaan tersebut menunjukkan bahwa PBL mampu meningkatkan pengetahuan serta mengembangkan keterampilan berpikir siswa. Pemecahan masalah yang dilakukan secara mandiri ini tentunya dapat memberikan suatu pengalaman konkret yang dapat digunakan untuk memecahkan masalah-masalah serupa, karena pengalaman tersebut akan memberikan makna tersendiri bagi siswa.

Model pembelajaran PBL menyuguhkan berbagai situasi bermasalah yang autentik dan bermakna kepada siswa, yang dapat berfungsi sebagai batu loncatan untuk investigasi dan penyelidikan. Diketahui bahwa pada model PBL harus dilakukan dengan serangkaian kegiatan dimulai dari dengan mencari data sampai hingga menarik kesimpulan dari permasalahan. Suprihatiningrum, (2013) menyatakan bahwa PBL adalah suatu model pembelajaran, yang mana peserta didik sejak awal dihadapkan pada suatu masalah kemudian diikuti oleh proses pencarian informasi yang bersifat student centered.

\section{KESIMPULAN}

Terdapat perbedaan antara siswa yang belajar dengan model pembelajaran PBL dengan Inquiry terhadap hasil belajar siswa di MTs Negeri 1 Rantauprapat. Nilai rata-rata hasil belajar siswa kelas VIII MTs Negeri 1 Rantauprapat dengan model pembelajaran PBL lebih baik dibandingkan dengan model pembelajaran Inquiry.

\section{REFERENSI}

Amir, T. 2010. Inovasi Pendidikan Melalui Problem Based Learning: Bagaimana Pendidik Memberdayakan Pembelajar Di Era Pengetahuan. Kencana Prenada Media Grup. Jakarta, 136 hal.

Dinullah, R. N. 2018. Perbedaan Model Problem Based Learning Dan Discovery-Inquiry Ditinjau Dari Hasil Belajar Matematika Siswa. Jurnal Mercumatika, 3(1): 1-8.

Hadiati, D., dan Nasution, M. Y. 2016. Perbedaan Hasil Belajar Yang Diajarkan Dengan Model Pembelajaran Problem Based Learning (PBL) dan Model Pembelajaran Inkuiri Pada Materi Sel Di SMA Negeri 16 Medan T.P. 2015/2016. Jurnal Pelita Pendidikan, 4 (1):8290 .

Handoyono, N. A., dan Arifin, Z. 2016. Pengaruh Inquiry Learning dan Problem-Based Learning Terhadap Hasil Belajar PKKR Ditinjau Dari Motivasi Belajar. Jurnal Pendidikan Vokasi, 6(1):31-42.

Mayasri, A., dan Rahmayani, R. F. 2019. Perbandingan Model Pembelajaran Problem Based Learning Dan Guided Inquiry Terhadap Kemampuan Berpikir Kritis Pada Materi Laju Reaksi. Jurnal Of Education Science, 5(1): 57-69. 
Mutmainnah, T., Ramlawati, dan Saenab, S. 2019. Perbandingan Model Pembelajaran Inkuiri Terbimbing Dan Problem Based Learning (PBL) Terhadap Hasil Belajar Peserta Didik Kelas VII SMP. Jurnal IPA Terpadu, 2(2): 1-11.

Pranoto, Harlita, dan Santoso, S. 2017. Perbandingan Model Pembelajaran Problem Based Learning dan Guided Discovery Learning Terhadap Keaktifan Siswa Kelas X SMA. Bioedukasi, 10(1): 18-22.

Putri, I. S., dan Agustyaningrum, N. 2017. Efektifitas Model Pembelajaran Discovery-Inquiry Untuk Meningkatkan Keterampilan Berpikir Rasional Siswa. Jurnal Mercumatika, 1(2): 97-103.

Rahayu, P. I., Rosidin, U., dan Abdurrahman. 2015. Perbandingan Hasil Belajar Siswa Antara Pembelajaran Menggunakan PBL dan Discovery Learning. Jurnal Pembelajaran Fisika, 3(5):1-9.

Riyanto, Y. 2001. Metodologi Penelitian Pendidikan. SIC. Surabaya. 97 hal.

Sudewi, N.L., Subagia, I.W., dan Tika, I.N. 2014. Studi Komparasi Penggunaan Model Pembelajaran Problem Based Learning (PBL) dan Kooperatif Tipe Group Investigation (GI) Terhadap Hasil Belajar Berdasarkan Taksonomi Bloom. Jurnal Pendidikan dan Pembelajaran IPA Indonesia, 4(1): 1-9

Suprihatiningrum, J. 2013. Strategi Pembelajaran Teori dan Aplikasi. Ar-Ruzz Media. Yogyakarta, 376 hal.

Unaenah, E., dan Muawiyah, I. 2019. Perbandingan Model Problem Based Learning dan Model Inquiry Terhadap Hasil Belajar IPA SD. Journal Of Islamic Primary Education, 2(2): 1018.

\section{Authors:}

Maharani Gultom, Program Studi Pendidikan Biologi, Fakultas Keguruan dan Ilmu Pendidikan, Universitas Labuhanbatu, Jl. Sisingamangaraja No. 126-A KM. 3,5 Aek Tapa, 21415, Sumatera Utara, Indonesia, email: maharanigultom.mpd@gmail.com

Dini Hariyati Adam, Program Studi Pendidikan Biologi, Fakultas Keguruan dan Ilmu Pendidikan, Universitas Labuhanbatu, Jl. Sisingamangaraja No. 126-A KM. 3,5 Aek Tapa, 21415, Sumatera Utara, Indonesia, email: dini-adam89@yahoo.com

Ika Cahastanti, Program Studi Pendidikan Biologi, Fakultas Keguruan dan Ilmu Pendidikan, Universitas Labuhanbatu, Jl. Sisingamangaraja No. 126-A KM. 3,5 Aek Tapa, 21415, Sumatera Utara, Indonesia, email: chastanti.ika@gmail.com

Zunaidy Abdullah Siregar, Program Studi Pendidikan Biologi, Fakultas Keguruan dan Ilmu Pendidikan, Universitas Labuhanbatu, Jl. Sisingamangaraja No. 126-A KM. 3,5 Aek Tapa, 21415, Sumatera Utara, Indonesia, email : zzunaidysiregar@gmail.com

This is an open-access article distributed under the terms of the Creative Commons Attribution License, which permits unrestricted use, distribution and reproduction in any medium, provided the original author and source are credited. (http://creativecommons.org/licenses/by/4.0/).

How to cite this article:

Gultom, M., Adam, D.H., Cahastanti, I., and Siregar, Z. A. 2020. Comparison of Problem Based Learning and Inquiry models on results of student learning in MTs Negeri 1 Rantauprapat. Simbiosa, 9(1):22-28. Doi. http://dx.doi.org/10.33373/sim-bio.v9i1.2308 